(2) Open Access Full Text Article

ORIGINAL RESEARCH

\title{
Computer-aided drug design and inhibitive effect of a novel nitrogenous heterocyclic compound and its mechanism on glioma U25 I cells and breast cancer MCF-7 cells
}

This article was published in the following Dove Press journal:

Drug Design, Development and Therapy

\section{Liyu Qian' \\ Yu Zhu ${ }^{2}$}

'Department of Tumor Surgery, The First Affiliated Hospital of Bengbu Medical College, Bengbu 233004, China; ${ }^{2}$ Tianjin Key Laboratory of Cerebral Vessels and Neuraldegenerative Disease, Department of Clinical Laboratory, Tianjin Huanhu Hospital, Tianjin 300350, China
Correspondence: Liyu Qian Department of Tumor Surgery, The First Affiliated Hospital of Bengbu Medical College, 287 Changhuai Road, Bengbu 233004, China

Email aqianliyu2006@163.com

Yu Zhu

Tianjin Key Laboratory of Cerebral Vessels and Neuraldegenerative Disease, Department of Clinical Laboratory, Tianjin Huanhu Hospital, 6 Jizhao Road, Jinnan District, Tianjin 300350, China Email zhuyutj@I26.com
Background: Glioma and breast cancer are severe malignant cancerous tumors that highlight the importance of developing new anti-cancer drugs. The aim of this study was to explore the effects of a novel nitrogenous heterocyclic compound on glioma and breast cancer cells and to determine its mechanism of action.

Methods: We designed and synthesized a novel nitrogenous heterocyclic compound, 3-(4amino-1H-benzo[d]imidazole-2-carboxamido)-4-oxo-3,4-dihydroimidazo[5,1-d][1,2,3,5] tetrazine-8-carboxamide, based on alkylglycerone phosphate synthase (AGPS) using computeraided drug design (CADD), and we measured its effect on the proliferation, invasion, cell cycle and apoptosis of U251 glioma and MCF-7 breast cancer cells. In addition, the compound's effect on the expression of tumor-related mRNA, circular RNAs (circRNAs) and long non-coding RNAs (lncRNAs) was explored.

Results: It was found that the nitrogenous heterocyclic compound could induce cell cycle arrest at the G2/M phase of U251/MCF-7 cells and activate apoptosis. Real-time PCR showed that the expression levels of tumor-related mRNA, circRNAs and lncRNAs were impacted.

Conclusion: We concluded that the nitrogenous heterocyclic compound inhibits the proliferation and invasion of U251 glioma and MCF-7 breast cancer cells through the induction of apoptosis and cell cycle arrest by regulating tumor-related genes.

Keywords: nitrogenous heterocyclic compound, glioma, breast cancer, proliferation, invasion

\section{Introduction}

Glioma and breast cancer are both severe malignant cancerous tumors with suboptimal therapeutic treatments, for example, the 5-year survival rate of malignant glioma patients is about $5 \%{ }^{1}$ and breast cancer is the most common invasive malignancy and the second leading cause of tumor-related death among women worldwide; ${ }^{2}$ there are excessive side-effects in current anti-cancer drugs, therefore, it is very important to develop new anti-cancer drugs. Previous studies have indicated that alkylglycerone phosphate synthase (AGPS) has a close association with tumor development. Overexpression of AGPS can increase the viability and migration potential of various tumor cells, including $231 \mathrm{MFP}, \mathrm{C} 8161$ melanoma, PC3 prostate cancer and primary breast cancer cells, and advance the growth and migration of the tumor cells, ${ }^{3}$ demonstrating the important role of AGPS in tumor development, Meanwhile, in our previous study it was also reported that AGPS silencing suppresses the potential of proliferation and 
invasion of U251 glioma cells; ${ }^{4,5}$ thus, we considered that AGPS may be a viable target for anti-cancer drugs.

Benzyl isothiocyanate is a natural compound that is extracted from cruciferase plants and shows anti-tumor activity in many tumor types. ${ }^{6,7}$ However, the potential application of this compound in cancer is limited due to the toxicity of the isothiocyanate moiety.

We designed and synthesized a novel nitrogenous heterocyclic compound, 3-(4-amino-1H-benzo[d]imidazole-2carboxamido)-4-oxo-3,4-dihydroimidazo[5,1-d][1,2,3,5] tetrazine-8-carboxamide, with reduced toxicity based on AGPS using computer-aided drug design (CADD) to improve potency and decrease the side effects. The effect of the nitrogenous heterocyclic compound on the proliferation and invasion of $\mathrm{U} 251$ glioma and MCF-7 breast cancer cells was explored, and the molecular mechanism was investigated to understand the anti-tumor effects of this compound.

\section{Methods}

\section{Computer-aided drug design and compound synthesis}

The AGPS three-dimensional structure (PDBID: 2UUV) was downloaded from the Protein Data Bank, and the molecular structure was drawn using ChemBioOffice2010. "CDOCKER ENERGY" was measured using Discovery Studio 3.5.

The compound was synthesized as follows: A solution of 5-amino-1H-imidazole-1,4-dicarboxamide (100 mmol) and aminoisocyanate $(100 \mathrm{mmol})$ in $300 \mathrm{~mL}$ of tetrahydrofuran was stirred at $60^{\circ} \mathrm{C}$ for $5 \mathrm{~h}$ to give 3-amino-4-oxo-3,4dihydroimidazo [5,1-d] [1,2,3,5] tetrazine-8-carboxamide. This intermediate was then reacted with 4-amino- $1 \mathrm{H}-$ benzo[d] imidazole-2-carboxylic acid $(100 \mathrm{mmol})$ at $60^{\circ} \mathrm{C}$ for $12 \mathrm{~h}$ to give the desired compound, 3-(4-amino- $1 \mathrm{H}-$ benzo[d] imidazole-2-carboxamido)-4-oxo-3,4-dihydroimidazo[5,1-d] $[1,2,3,5]$ tetrazine-8-carboxamide (95\% purity). All the major chemicals were purchased from Weiran Biotech (Jinan, China). ${ }^{1} \mathrm{HNMR}$ (DMSO-d6 $\left.400 \mathrm{MHz}\right) \delta 8.70$ (s, 1H), 8.37 $(\mathrm{s}, 2 \mathrm{H}), 8.03(\mathrm{~s}, 1 \mathrm{H}), 6.97(\mathrm{~d}, J=8.4 \mathrm{~Hz}, 1 \mathrm{H}), 6.89(\mathrm{dd}$, $J=6.4 \mathrm{~Hz}, 1 \mathrm{H}), 6.46$ (d, J=8.2 Hz, 1H), 6.27 (s, 2H), 5.10 (s, 1H), $4.51(\mathrm{~s}, 1 \mathrm{H})$. MS (ESI) m/z $354.1(\mathrm{M}+1)^{+}$.

\section{Cell lines and culture}

Rat adrenal medulla PC12 (ATCC Number: CRL-1721), human glioma U251 (ATCC Number: TCP-1018), normal breast MCF10A (ATCC Number: CRL-10317) and breast cancer MCF-7 (ATCC Number: HTB-22) cell lines were purchased from the American Type Culture Collection (ATCC, Manassas, VA, USA). The PC12 cell line was cultured in Ham's F12K (with 10\% fetal bovine serum), while the U251, MCF10A and MCF-7 cell lines were cultured in DMEM (with 10\% fetal bovine serum). Both above culture media contained $100 \mathrm{U} / \mathrm{mL}$ of penicillin and $100 \mathrm{mg} / \mathrm{mL}$ of streptomycin and were maintained at $37^{\circ} \mathrm{C}$ with $5 \% \mathrm{CO}_{2}$. The heterocyclic or isothiocyanate compounds were dissolved by DMSO and diluted by DMEM without fetal bovine serum.

\section{MTT assays}

PC12/U251/MCF10A/MCF-7 cells were cultured in 96-well plates $\left(3 \times 10^{3} /\right.$ well $)$ overnight. The cells were treated with the nitrogenous heterocyclic compound or benzyl isothiocyanate at various concentrations $(0,10,20,50,100,200,500 \mu \mathrm{M})$ for $72 \mathrm{~h}$. MTT $(20 \mu \mathrm{L})$ was added, and the cells were cultured at $37^{\circ} \mathrm{C}$ for $4 \mathrm{~h}$. The solution was removed, and then $150 \mu \mathrm{L}$ of DMSO was added at $37^{\circ} \mathrm{C}$ for $10 \mathrm{~min}$, after which time the OD was determined at $490 \mathrm{~nm}$. The inhibitory rate of the drugs on the cells was calculated as follows: $\%$ Inhibition $=$ $\left(1-\right.$ OD value treatment group $/ \mathrm{OD}$ value $\left._{0 \mu \mathrm{M}}\right) \times 100 \%$.

\section{Flow cytometry assay}

U251/MCF-7 cells ( $2 \times 10^{5} /$ well) were cultured in 6-well plates in the presence of the nitrogenous heterocyclic compound ( 50 and $100 \mu \mathrm{M}$ ) at $37^{\circ} \mathrm{C}$ for $72 \mathrm{~h}$. After the cells were digested, washed with cold PBS, and stained with Annexin V-FITC (Annexin V-FITC Apoptosis Detection Kit, Beyotime Biotechnology, Shanghai, China) at room temperature away from light, for $15 \mathrm{~min}$, apoptosis was measured by flow cytometry at $488 \mathrm{~nm}$. Likewise, after the cells were treated with 20 and $50 \mu \mathrm{M}$ of the nitrogenous heterocyclic compound at $37^{\circ} \mathrm{C}$ for $72 \mathrm{~h}$, fixed using $70 \%$ absolute alcohol at $4^{\circ} \mathrm{C}$ overnight, and stained by propidium iodide (Sigma-Aldrich, St. Louis, MO, USA) at room temperature away from light, for $30 \mathrm{~min}$, the cell cycle was analyzed using flow cytometry at $488 \mathrm{~nm}$.

\section{Caspase- $3 / 8$ activity assays}

U251/MCF-7 cells $\left(2 \times 10^{5} /\right.$ well $)$ were cultured in 6-well plates in the presence of the nitrogenous heterocyclic compound $(20$ and $50 \mu \mathrm{M})$ at $37^{\circ} \mathrm{C}$ for $72 \mathrm{~h}$. Caspase- $3 / 8$ activity was measured using caspase detection kits (ImmunoChemistry Technologies LLC, Bloomington, MN, USA) and a microplate reader at $488 \mathrm{~nm}$.

\section{Transwell assay}

U251/MCF-7 cells ( $2 \times 10^{5} /$ well) were cultured in 6-well plates in the presence of the nitrogenous heterocyclic compound (20 and $50 \mu \mathrm{M}$ ) at $37^{\circ} \mathrm{C}$ for $72 \mathrm{~h}$. After digestion by Trypsin-EDTA, DMEM was used to suspend the cells $\left(5 \times 10^{5} / \mathrm{mL}\right)$, and 100 $\mu \mathrm{L}$ of the suspension was added into the Transwell (Corning, NY, USA) upper chamber with $25 \mu \mathrm{L}$ Matrigel $(200 \mu \mathrm{g} / \mathrm{mL}$, 
BD Biosciences, San Jose, CA, USA). DMEM containing $10 \%$ fetal bovine serum (FBS) $(600 \mu \mathrm{L})$ was added into the lower chamber, and the cells were cultured at $37^{\circ} \mathrm{C}$ for $24 \mathrm{~h}$. The membrane was fixed using $4 \%$ methyl ester at room temperature for $10 \mathrm{~min}$ and stained by $0.01 \%$ crystal violet at room temperature for $20 \mathrm{~min}$, and then the number of migrating cells was counted using a light microscope $(\times 200)$.

\section{Western blot assay}

U251/MCF-7 cells $\left(2 \times 10^{5} /\right.$ well $)$ were cultured in 6-well plates in the presence of the nitrogenous heterocyclic compound ( 20 and $50 \mu \mathrm{M}$ ) at $37^{\circ} \mathrm{C}$ for $72 \mathrm{~h}$. The cells were lysed, and the total proteins were extracted by centrifugation at $12,000 \mathrm{~g}$ at $4^{\circ} \mathrm{C}$ for $10 \mathrm{~min}$ using protein extraction buffer (Bioo Scientific, Austin, TX, USA). Protein was measured using the Bradford assay (Beyotime Biotechnology, Shanghai, China), and $50 \mathrm{ng}$ of the protein was separated via $12 \%$ SDSPAGE and then transferred onto a polyvinylidene fluoride membrane. The membrane was blocked using 1\% BSA at $37^{\circ} \mathrm{C}$ for $1 \mathrm{~h}$. The membrane was incubated with AGPS (1:2,000, sc-374201), p21 (1:1,500; sc-166630), p27 (1:1,500; sc-71813), Bcl-2 (1:1,500; sc-23960), survivin (1:1,500; sc-101433) and Bim (1:1,500; sc-374358) antibodies at $4^{\circ} \mathrm{C}$ overnight and was then incubated at $37^{\circ} \mathrm{C}$ for $1 \mathrm{~h}$ with peroxidase-labeled anti-rabbit immunoglobulin $\mathrm{G}(1: 2,000)$. The membrane was washed three times with PBS containing $0.05 \%$ Tween 20 . The membrane was visualized using Immobilon Western chemiluminescent horseradish peroxidase substrate (EMD Millipore, Billerica, MA, USA). $\beta$-Actin $(1: 5,000 ; \mathrm{sc}-58673)$ was used as the control. All antibodies were purchased from Santa Cruz (Dallas, TX, USA).

\section{Quantitative real time polymerase chain reaction ( $\mathrm{qRT}-\mathrm{P}) \mathrm{CR}$ assay}

U251/MCF-7 cells $\left(2 \times 10^{5} /\right.$ well $)$ were cultured in 6 -well plates in the presence of the nitrogenous heterocyclic compound $(20$ and $50 \mu \mathrm{M})$ at $37^{\circ} \mathrm{C}$ for $72 \mathrm{~h}$. Trizol (Invitrogen, Thermo Fisher Scientific, Waltham, MA, USA) was used to extract the total RNA from each group, and an RT-PCR kit (Takara Bio Inc., Kusatsu, Shiga Prefecture, Japan) was used in reverse transcription of the RNA into DNA. A $2 \mu \mathrm{L}$ aliquot of the RT product was used to perform the PCR reaction. Total RNA was then reverse transcribed and the expression of mRNAs, circRNAs and lncRNAs was detected using the realtime PCR assay (Applied Biosystems 7500 Real-Time PCR System, Thermo Fisher Scientific, Waltham, MA, USA). The PCR conditions were as follows: denaturation at $95^{\circ} \mathrm{C}$ for $10 \mathrm{~min}$, followed by 40 cycles at $95^{\circ} \mathrm{C}$ for $15 \mathrm{~s}, 60^{\circ} \mathrm{C}$ for $60 \mathrm{~s}$ and a final elongation at $95^{\circ} \mathrm{C}$ for $15 \mathrm{~s}$. The genes were
Table I Quantitative real time polymerase chain reaction primers in the experiments

\begin{tabular}{|c|c|}
\hline Gene & Primers \\
\hline \multirow[t]{2}{*}{ P2I } & Forward: 5'-CATGGGTTCTGACGGACATC-3' \\
\hline & Reverse: 5'-TGCCGAAGTCAGTTCCTTGT-3' \\
\hline \multirow[t]{2}{*}{ P27 } & Forward: 5'-CATTCCATGAAGTCAGCGAT-3' \\
\hline & Reverse: 5'-CGTCAAACGTAAACAGCTCG-3' \\
\hline \multirow[t]{2}{*}{ BCl-2 } & Forward: 5'-CGTACAGTTCCACAAAGGCA-3' \\
\hline & Reverse: 5'-ATGTGTGTGGAGAGCGTCAA-3' \\
\hline \multirow[t]{2}{*}{ Survivin } & Forward: 5'-TCCGCAGTTTCCTCAAATTC-3' \\
\hline & Reverse: 5'-GTTGCGCTTTCCTTTCTGTC-3' \\
\hline \multirow[t]{2}{*}{ Bim } & Forward: 5'-GATAGTGGTTGAAGGCCTGG-3' \\
\hline & Reverse: 5'-CСTCCCTACAGACAGAGCCA-3' \\
\hline \multirow[t]{2}{*}{ DQ786243 } & Forward: AATCGGCTCTGGAAGGTGAA \\
\hline & Reverse: CTGCTGTTCCGATGGTGTCTT \\
\hline \multirow[t]{2}{*}{ HOXD-ASI } & Forward: GGCTCTTCCCTAATGTGTGG \\
\hline & Reverse: CAGGTCCAGCATGAAACAGA \\
\hline \multirow[t]{2}{*}{ CCATI } & Forward: CATTGGGAAAGGTGCCGAGA \\
\hline & Reverse: ACGCTTAGCCATACAGAGCC \\
\hline \multirow[t]{2}{*}{ HULC } & Forward: CAGGAAGAGTCGTCACGAGAACCAG \\
\hline & Reverse: CTTCTTGCTTGATGCTTTGGTCTGT \\
\hline \multirow[t]{2}{*}{ GAS5 } & Forward: CTTCTGGGCTCAAGTGATCCT \\
\hline & Reverse: TTGTGCCATGAGACTCCATCAG \\
\hline \multirow[t]{2}{*}{ CASC2 } & Forward: GCACATTGGACGGTGTTTCC \\
\hline & Reverse: CCCAGTCCTTCACAGGTCAC \\
\hline \multirow[t]{3}{*}{ ANCR } & Forward: GACATTTCCTGAGTCGTCTTCG \\
\hline & AACGGAC \\
\hline & Reverse: TAGTGCGATTTAGAGCTGTACAAGTTTC \\
\hline \multirow[t]{2}{*}{ MEG3 } & Forward: TTTTGTGCCCAAGGCTCCTGGA \\
\hline & Reverse: AGGGACTCAAGGAGCCAGGTTA \\
\hline \multirow[t]{2}{*}{ circUBAP2 } & Forward: AGCCTCAGAAGCCAACTCCTTTG \\
\hline & Reverse: TCAGGTTGAGATTTGAAGTCAAGAT \\
\hline \multirow[t]{2}{*}{ circZNF292 } & Forward: GCTCAAGAGACTGGGGTGTG \\
\hline & Reverse: AGTGTGTGTTCTGGGGCAAG \\
\hline \multirow[t]{4}{*}{ circTCF25 } & Forward: CGGAATTCTGAAATATGCTATCTTA \\
\hline & CAGAGAGAGCGCTGTACAGCATGGA \\
\hline & Reverse: CGGGATCCTCAAGAAAAAATATATT \\
\hline & CACCTCCAGGGAACATGGTGAGCGC \\
\hline \multirow[t]{2}{*}{ circHIPK3 } & Forward: TATGTTGGTGGATCCTGTTCGGCA \\
\hline & Reverse: TGGTGGGTAGACCAAGACTTGTGA \\
\hline \multirow[t]{2}{*}{$\operatorname{circCdrl}$} & Forward: GTGTCTCCAGTGTATCGGCG \\
\hline & Reverse: TACTGGCACCACTGGAAACC \\
\hline \multirow[t]{2}{*}{ circZKSCANI } & Forward: AGTCCCACTTCAAACATTCGTCT \\
\hline & Reverse: CACCTTCACTATTACGATACCATCC \\
\hline \multirow[t]{2}{*}{ circlTCH } & Forward: GCAGAGGCCAACACTGGAA \\
\hline & Reverse: TCCTTGAAGCTGACTACGCTGAG \\
\hline \multirow[t]{2}{*}{ circMTOI } & Forward: GAGCTGTAGAAGATCTTATTC \\
\hline & Reverse: CACAGGCCATCCAAGGCATC \\
\hline \multirow[t]{2}{*}{$\beta$-actin } & Forward: AGGCACCAGGGCGTGAT \\
\hline & Reverse: GCCCACATAGGAATCCTTCTGAC \\
\hline
\end{tabular}

normalized using $\beta$-actin as a control. The full details of the primers used in these experiments are shown in Table 1.

\section{Statistical analysis}

Experimental data are represented by $\mathrm{x} \pm \mathrm{s}$. SPSS 11.0 statistical software was used to perform one-way analysis of variance (ANOVA) and a $P$-value $\leq 0.05$ was considered of statistical significance. 


\section{Results}

The expression of AGPS of PCI2, U25I, MCFIOA and MCF-7 cells

The Western blotting showed an increased expression of AGPS in U251 and MCF-7 cells compared with PC12 and MCF10A cells, thus demonstrating that there was an overexpression of AGPS in tumor cells (Figure 1A). The result also showed that nitrogenous heterocyclic compound suppressed the expression of AGPS in U251 and MCF-7 cells, indicating its target for AGPS (Figure 1B).

\section{The effect of the nitrogenous} heterocyclic compound and benzyl isothiocyanate on the proliferation of U25I and MCF-7 cells

Using virtual screening, we designed and synthesized the nitrogenous heterocyclic compound 3-(4-amino-1H-benzo[d] imidazole-2-carboxamido)-4-oxo-3,4-dihydroimidazo[5,1-d] $[1,2,3,5]$ tetrazine-8-carboxamide (Figure 2A); the 2D and 3D combined mode with amino acid residues of AGPS is shown

A

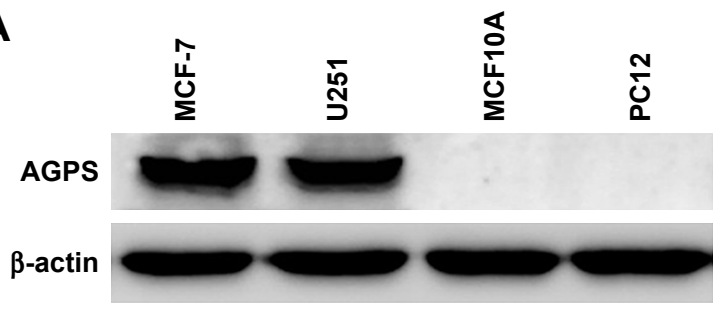

B

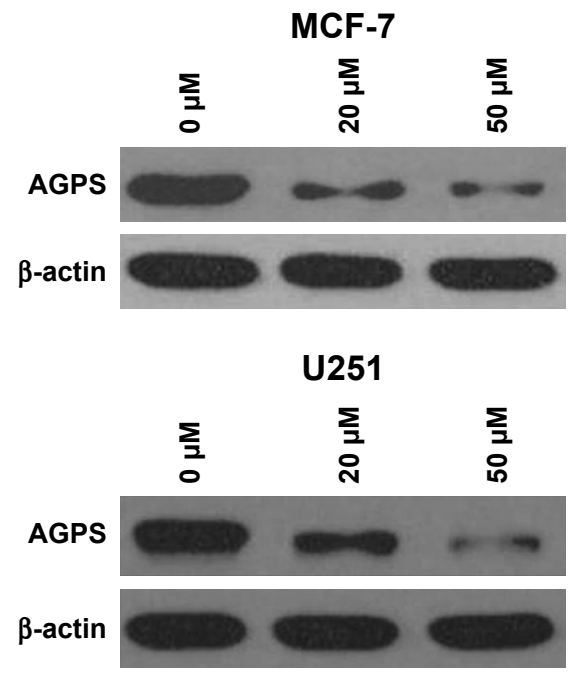

Figure I The expression of AGPS in PCI2, U25I, MCFIOA and MCF-7 cell lines. Notes: (A) The Western blotting assay showed that there was increased expression of AGPS in U25I and MCF-7 cell lines compared with PCI2 and MCFIOA cell lines. (B) The Western blotting assay showed that nitrogenous heterocyclic compound suppressed the expression of AGPS in U25I and MCF-7 cell lines. $\beta$-actin served as a reference.

Abbreviation: AGPS, alkylglycerone phosphate synthase. in Figure 2B and C. The synthetic procedure to prepare the nitrogenous heterocyclic compound is shown in Figure 2D. Furthermore, the MTT assay showed that the nitrogenous heterocyclic compound (Figure 2E) and benzyl isothiocyanate (Figure 2F) inhibit the proliferation of PC12, U251, MCF10A and MCF-7 cell lines in a dose-dependent manner. The results showed that after the nitrogenous heterocyclic compound and benzyl isothiocyanate acted on the PC12, U251, MCF10A and MCF-7 cells for $72 \mathrm{~h}$, nitrogenous heterocyclic compound was less toxic to the normal than non-cancerous cells due to a lower level of growth inhibition compared with benzyl isothiocyanate (Figure 2G), indicating increased safety and cancer-targeting ability of the nitrogenous heterocyclic compound compared to benzyl isothiocyanate.

Nitrogenous heterocyclic compound concentrations that were non-toxic $(20 \mu \mathrm{M}$, inhibition rate $<5 \%)$ or that had low toxicity ( $50 \mu \mathrm{M}$, inhibition rate $<15 \%$ ) in $\mathrm{U} 251$ and MCF-7 cells were used in subsequent experiments to minimize the effects on cell proliferation, with $0 \mu \mathrm{M}$ serving as the control group.

\section{The effect of the nitrogenous heterocyclic} compound on the cell cycle of U25I and MCF-7 cells

Compared to the control group's effect on U251 and MCF-7 cells, the nitrogenous heterocyclic compound at 20 and $50 \mu \mathrm{M}$ resulted in a significant decrease in the number of cells in the G1 phase and an increase in the number of cells in the $\mathrm{G} 2 / \mathrm{M}$ phase after $72 \mathrm{~h}$ (Figure 3), thus demonstrating that the nitrogenous heterocyclic compound arrests the cell cycle of U251 and MCF-7 cells in G2/M phase.

\section{The effect of the nitrogenous heterocyclic compound on the apoptosis of U25I and MCF-7 cells}

Flow cytometry showed an increase in apoptosis after treating U251 and MCF-7 cells with the nitrogenous heterocyclic compound at 50 and $100 \mu \mathrm{M}$ for $72 \mathrm{~h}$, which demonstrates that the nitrogenous heterocyclic compound could cause the apoptosis of U251/MCF-7 cells. Furthermore, we found that the nitrogenous heterocyclic compound induced increased caspase-3/8 activity in U251 and MCF-7 cells (Figure 4).

\section{The effect of the nitrogenous heterocyclic compound on the invasion of U25I and MCF-7 cells}

To study the effect of the nitrogenous heterocyclic compound on the invasion of U251 and MCF-7 cells, we examined the 
A<smiles>NC(=O)c1ncn2c(=O)n(NC(=O)c3nc4c(N)cccc4[nH]3)nnc12</smiles>

B<smiles>[Mg][Mg]</smiles>

\section{ALA}

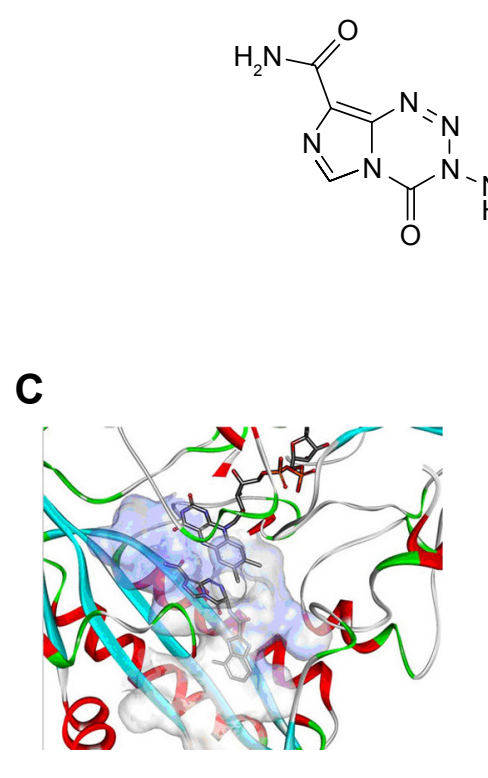

D

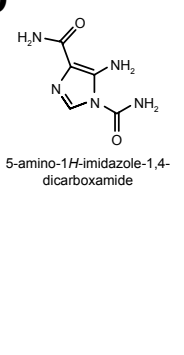

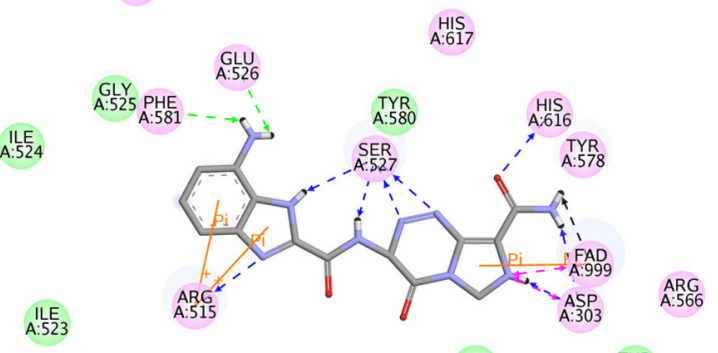

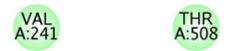

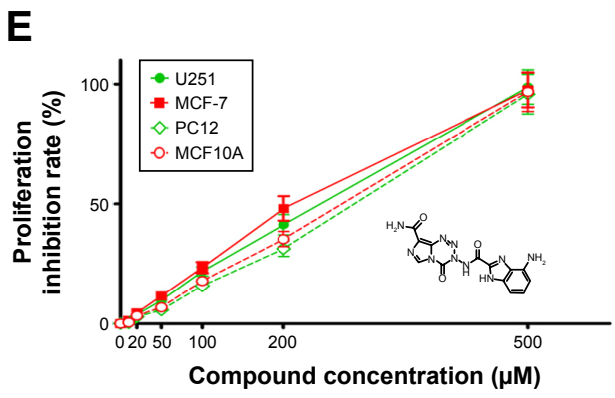

F

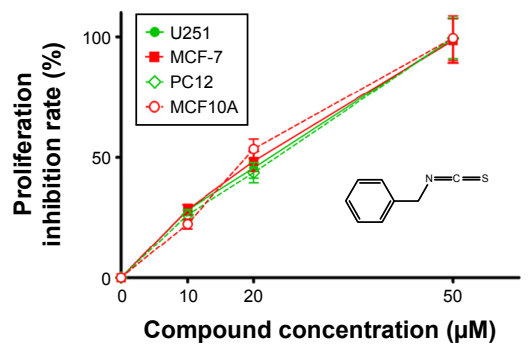

G

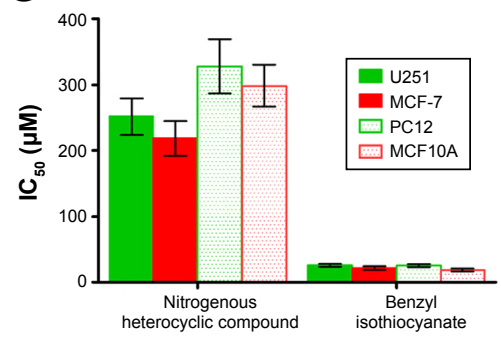

Figure 2 The design of the nitrogenous heterocyclic compound and its inhibition in the proliferation of glioma and breast cancer cell lines.

Notes: The structure (A), 2D combined mode with amino acid residues of AGPS (B), where the green circle and green line represent a hydrophobic bond, the pink circle and blue line represent a hydrogen bond, and the orange line represents a pi bond (a covalent bond) in the interactions of the compounds, and 3D combined mode (C) with AGPS and the nitrogenous heterocyclic compound. (D) The synthetic procedure to prepare the nitrogenous heterocyclic compound. (E) The inhibitive effect of the nitrogenous heterocyclic compound on proliferation of PCI2, U25I, MCFIOA, and MCF-7 cell lines as determined by the MTT assay. (F) The inhibitive effect of benzyl isothiocyanate on proliferation of PCI2, U25I, MCFIOA, and MCF-7 cell lines as determined by the MTT assay. (G) The IC 50 of the nitrogenous heterocyclic compound and benzyl isothiocyanate in PCI2, U25I, MCFIOA, and MCF-7 cell lines.

Abbreviation: AGPS, alkylglycerone phosphate synthase.

invasion ability of U251 and MCF-7 cells using a transwell assay. Cell invasion significantly decreased after treatment with the nitrogenous heterocyclic compound compared to that of the control group, thus demonstrating that the nitrogenous heterocyclic compound affects the invasion ability of U251 and MCF-7 cells (Figure 5).

\section{The effect of the nitrogenous heterocyclic compound on the expression of tumor-related genes}

The real time PCR assay showed that treatment of U251 and MCF-7 cells with the nitrogenous heterocyclic compound at 20 and $50 \mu \mathrm{M}$ for $72 \mathrm{~h}$ resulted in significantly increased protein and mRNA expression of p27, p21 and Bim and decreased expression of Bcl-2 and survivin. The nitrogenous heterocyclic compound was also found to suppress the expression of circRNAs circUBAP2, circZNF292, circHIPK3, circTCF25, and circCdr1, as well as 1ncRNAs H19, DQ786243, HOXD-AS1, CCAT1, and HULC, while it increased the expression of circRNAs circZKSCAN1, circMTO1, and circITCH, as well as 1ncRNAs GAS5, CASC2, ANCR, and MEG3 (Figure 6).

\section{Discussion}

Both glioma and breast cancer are the most common types of cancer, and it remains a huge challenge to public health not just in China but throughout the world; thus, it is important to develop new cancer-targeting drugs with decreased toxicity. 
A

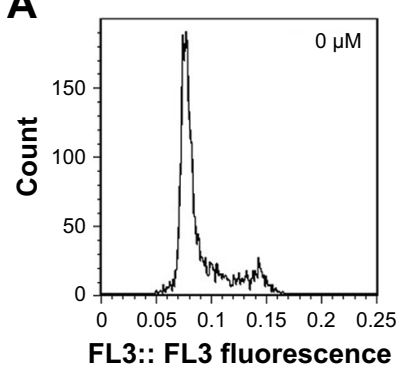

B

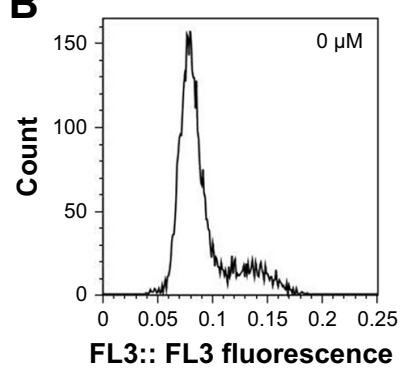

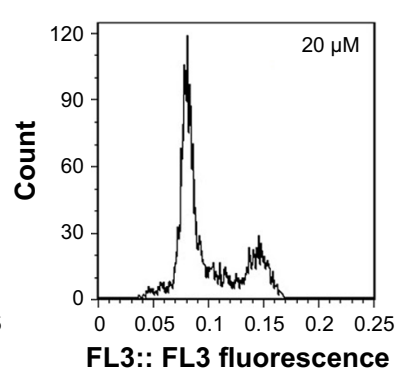
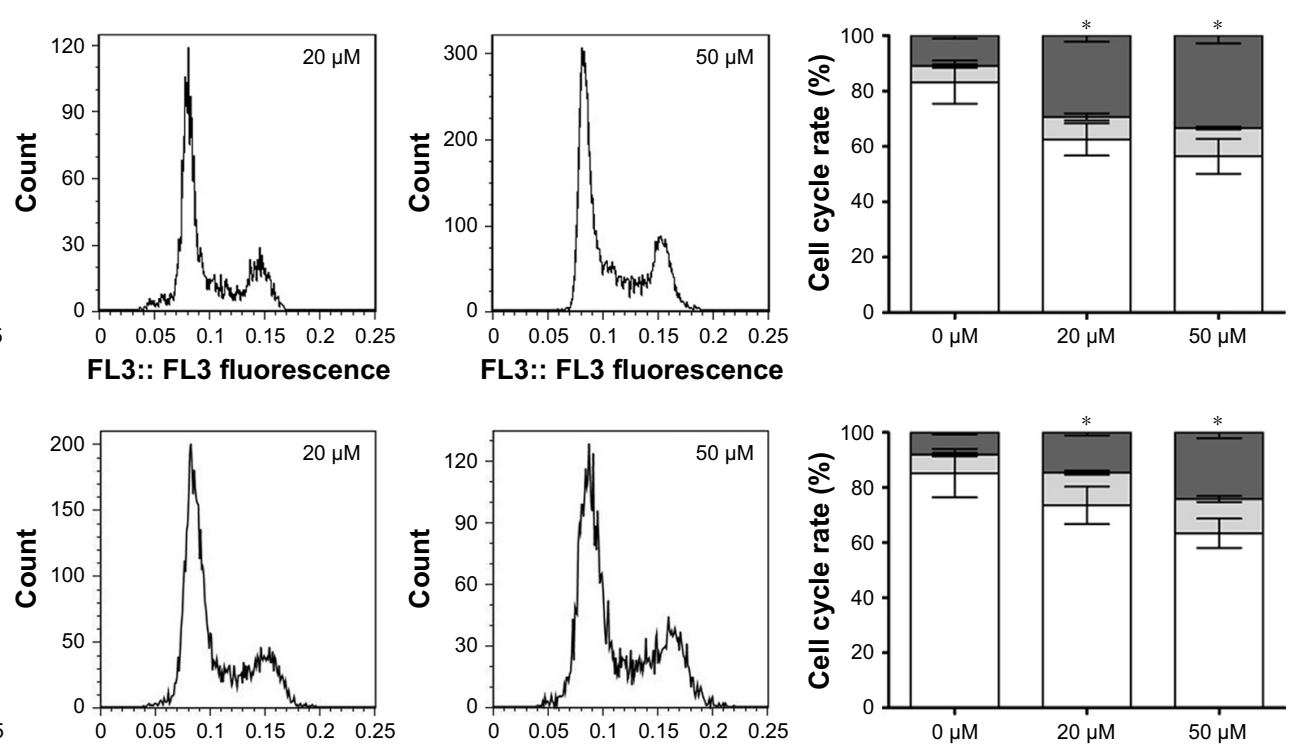

FL3:: FL3 fluorescence FL3:: FL3 fluorescence

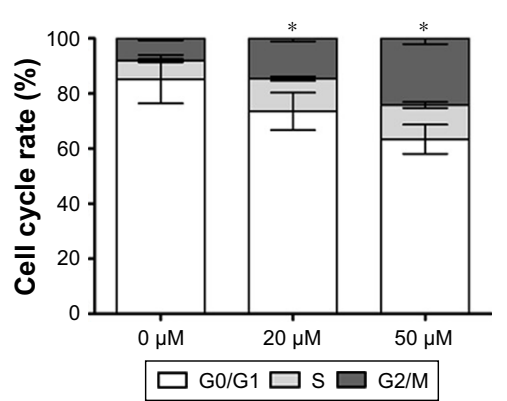

Figure 3 Effect of the nitrogenous heterocyclic compound on the cell cycle of U25I glioma and MCF-7 breast cancer cell lines.

Notes: An increased number of cells in the G2/M phase of U25I glioma (A) and MCF-7 breast cancer (B) cell lines was observed after treatment with the nitrogenous heterocyclic compound. *compared to the $0 \mu \mathrm{M}$ group, $P<0.05$.

It has been reported that benzyl isothiocyanate demonstrates anti-tumor activity; however, the potential application of this compound is limited due to its toxicity. ${ }^{8}$ Increased expression of AGPS in human U251 glioma and MCF-7 breast cancer cell lines was observed compared to non-cancer PC12 and MCF10A cell lines, indicating that AGPS may be a suitable target for anti-tumor drug therapy. Therefore, we hoped to modify the structure of benzyl isothiocyanate to improve its
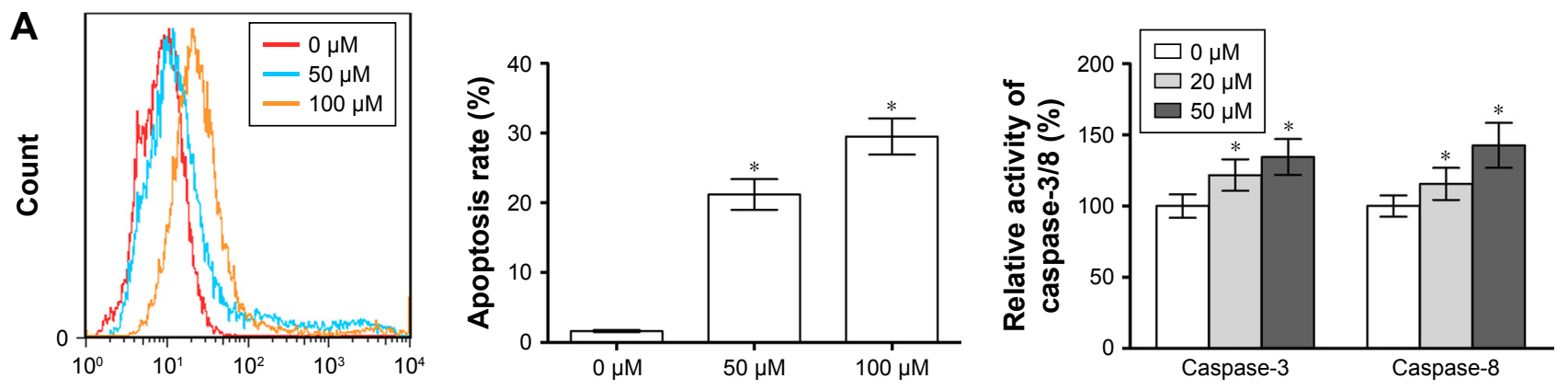

FL1:: FL1 fluorescence
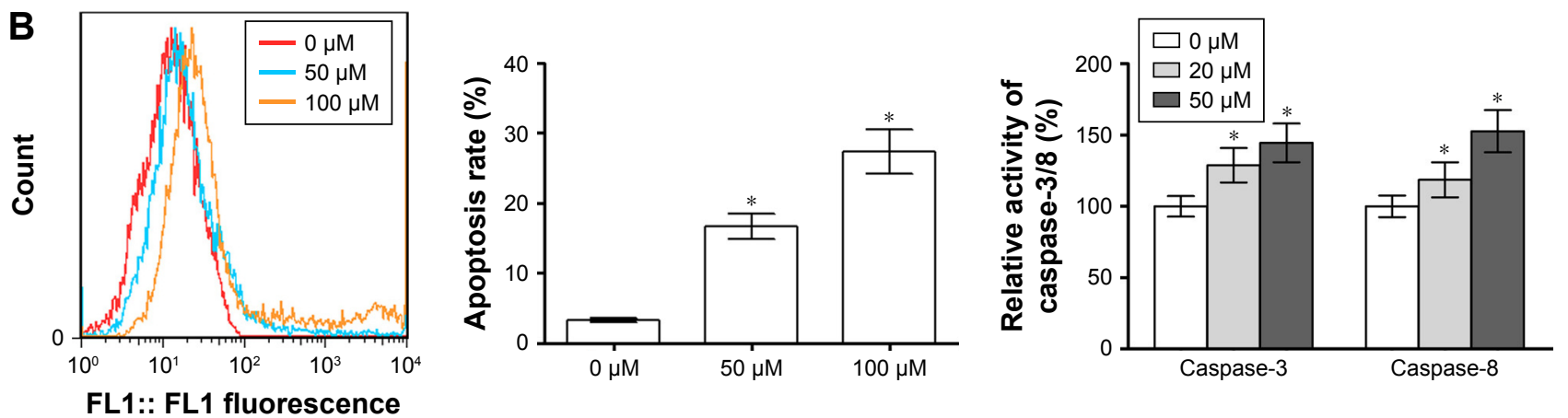

Figure 4 Effect of the nitrogenous heterocyclic compound on the apoptosis of U25I glioma and MCF-7 breast cancer cell lines.

Notes: Increased apoptosis and caspase-3/8 activity was observed in U25I glioma (A) and MCF-7 breast cancer (B) cell lines after treatment with the nitrogenous heterocyclic compound. *compared to the $0 \mu \mathrm{M}$ group, $P<0.05$. 
A

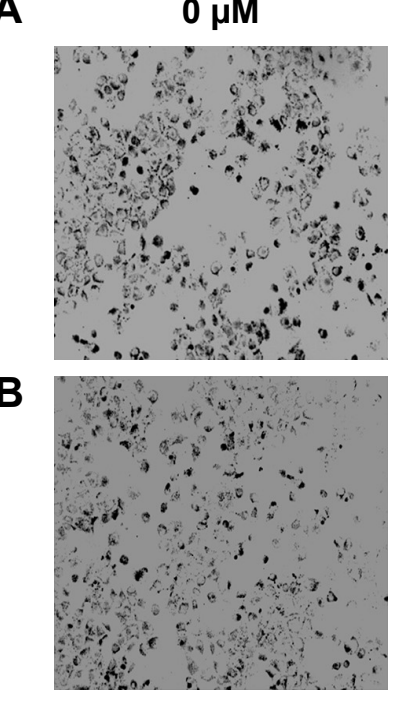

$20 \mu \mathrm{M}$
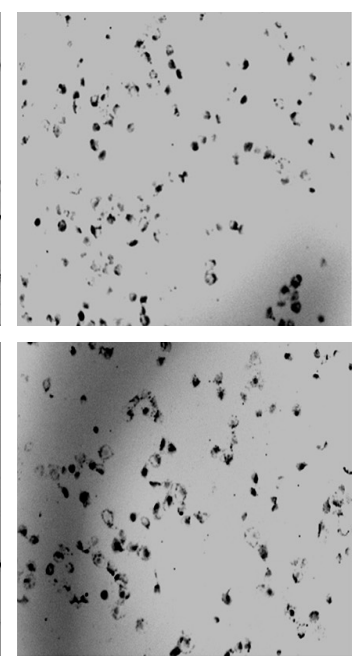

$50 \mu \mathrm{M}$

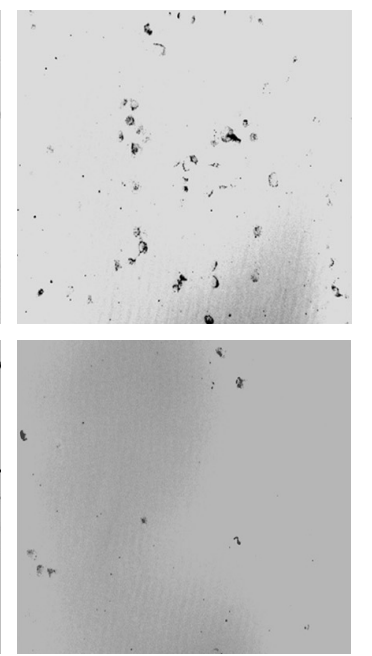

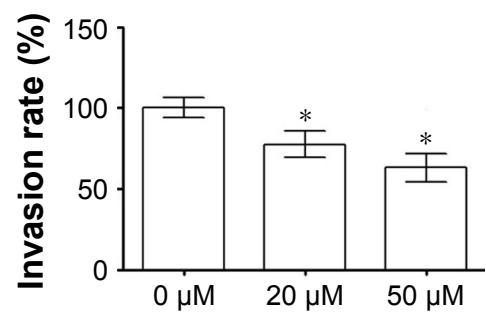

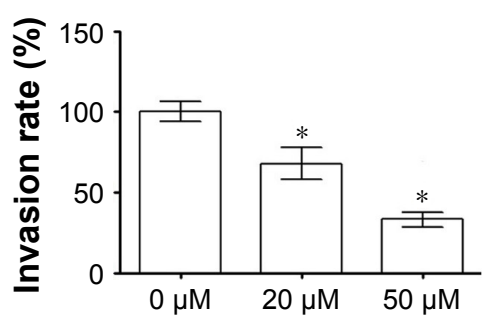

Figure 5 Effect of the nitrogenous heterocyclic compound on the invasion of U25I glioma and MCF-7 breast cancer cell lines.

Notes: Decreased invasion potential was observed in U25I glioma (A) and MCF-7 breast cancer (B) cell lines after treatment with the nitrogenous heterocyclic compound (magnification $\times 200$ ). *compared to the $0 \mu \mathrm{M}$ group, $P<0.05$.

selectivity for cancer cells and develop a potentially new drug by CADD.

In a previous study, we designed and synthesized an isothiocyanate derivative by CADD targeting AGPS, predicted the ADME (absorption, distribution, metabolism, excretion) and toxicity, and investigated the inhibitory effect of the compounds on the proliferation and invasion of glioma U251 cells, providing the basis for further development and clinical application of a nitrogenous heterocyclic compound. ${ }^{9}$

In order to obtain a comprehensive understanding of the anti-tumor activity associations among the candidate compounds and then further optimize the lead compound structure, we investigated the inhibitive effect of nitrogenous heterocyclic compound in U251 and MCF-7 cells.

We found that the nitrogenous heterocyclic compound had increased safety and cancer-targeting ability compared to that of benzyl isothiocyanate via affecting the proliferation and invasion of $\mathrm{U} 251$ glioma and MCF-7 breast cancer cells by inducing apoptosis and cell cycle arrest.

Anti-oncogenes p27 and p21 and cyclin-CDK are important mechanisms that are known to regulate the cell cycle. ${ }^{10-12}$ The combination of $\mathrm{p} 21$ with cyclin and CDK suppresses kinase activity and causes cell cycle arrest; $\mathrm{p} 27$ is also known to prevent the transition of cells from the G2 to the $\mathrm{M}$ phase and inhibit the cell cycle of tumor cells. ${ }^{13,14}$ Our study found that the nitrogenous heterocyclic compound increased the expression of $\mathrm{p} 27$ and $\mathrm{p} 21$, which suppressed the proliferation of $\mathrm{U} 251$ and MCF-7 cells.
Bcl-2 and survivin are known apoptosis-associated genes that inhibit cell apoptosis by suppressing the activation of caspase, ${ }^{15-17}$ while Bim is an apoptosis promoting gene that causes tumor cell apoptosis. ${ }^{18}$ In this study, the nitrogenous heterocyclic compound was found to decrease the expression of Bcl-2 and survivin and increase the expression of Bim, thus providing a mechanism for the induction of apoptosis in U251 and MCF-7 cells.

All of the Wnt/ $\beta$-catenin, PI3K-Akt, JAK/STAT, and MAPK/ERK signal pathways play an important role in the function of p27, p21, Bcl-2, survivin and Bim, thus we considered that they may also play an important role in the anti-tumor activity of nitrogenous heterocyclic compound.

Although their mechanism in the tumor process is not well understood, circRNAs and lncRNAs are considered important targets for anti-tumor drug therapy. Our study showed that the nitrogenous heterocyclic compound reduced the expression of circRNAs circUBAP2, circZNF292, circHIPK3, circTCF25 and circCdr1 and lncRNAs H19, DQ786243, HOXD-AS1, CCAT1 and HULC, which are known oncogenes. Meanwhile, the compound increased the expression of circRNAs circZKSCAN1, circMTO1 and circITCH and lncRNAs GAS5, CASC2, ANCR and MEG3, which are known tumor suppressor genes. These results suggest a potential role for circRNAs and lncRNAs in the nitrogenous heterocyclic compound. The involved signal pathways of lncRNAs and circRNAs are shown in Table 2, and suggest that there is a possibility that the nitrogenous heterocyclic compound affects tumor cells via 


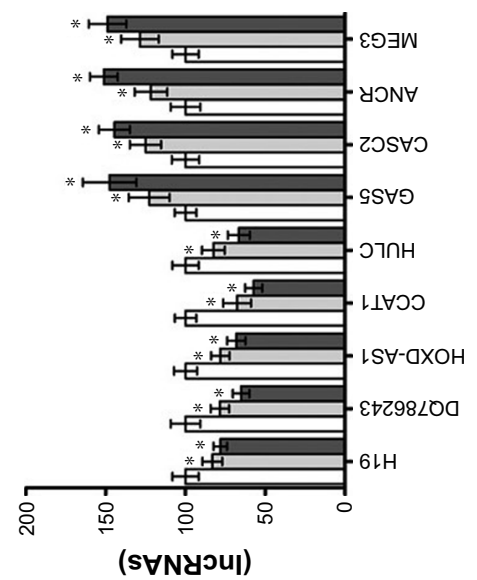

(\%) uo!̣ssəдdxə әм!ฺе|әу

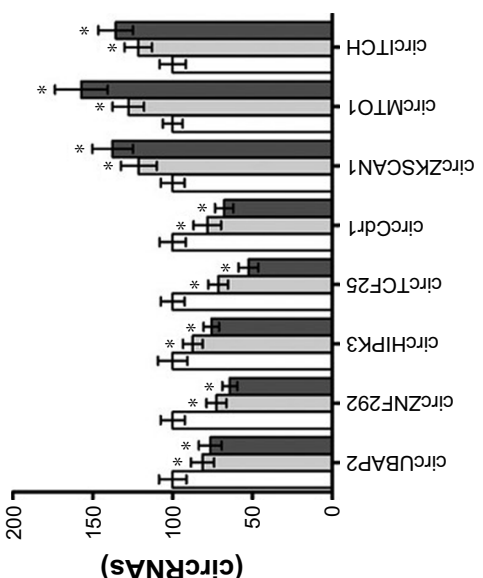

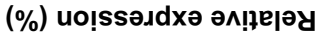

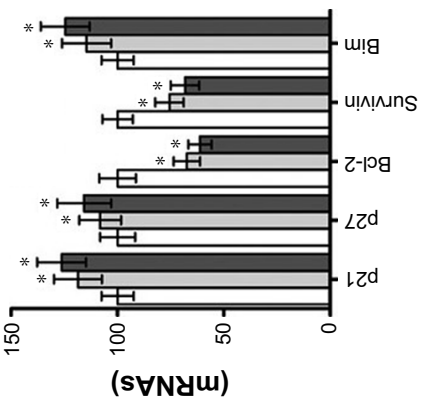

(\%) uo!̣ssəudxə әм!ฺЕ|әу

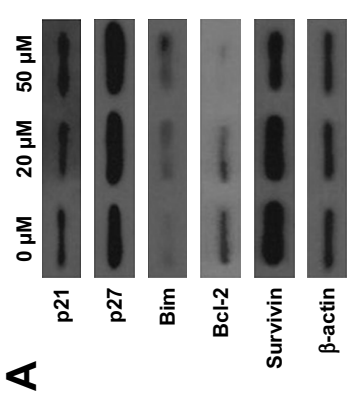

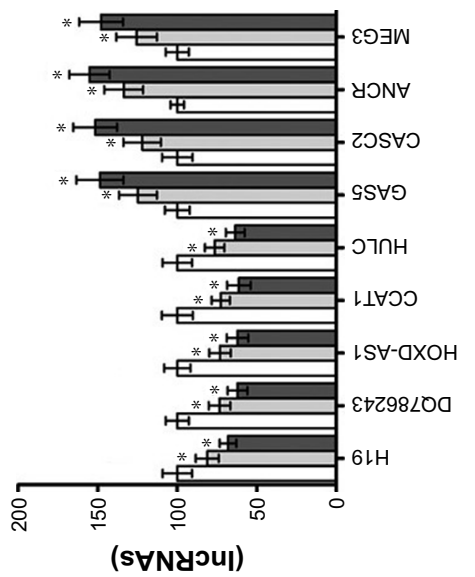

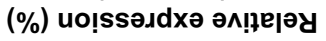
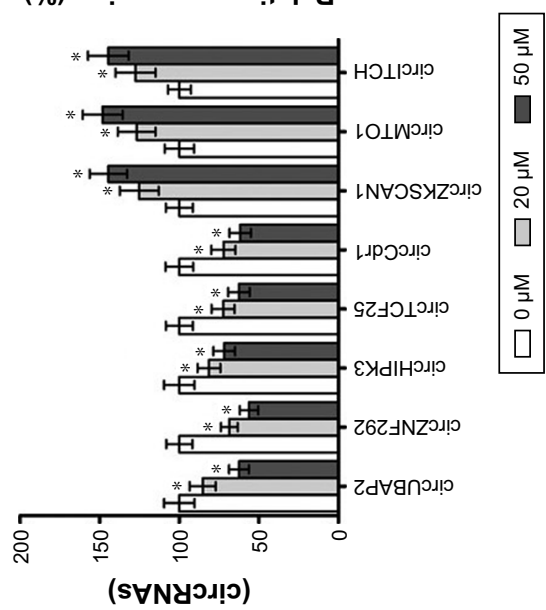

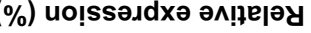

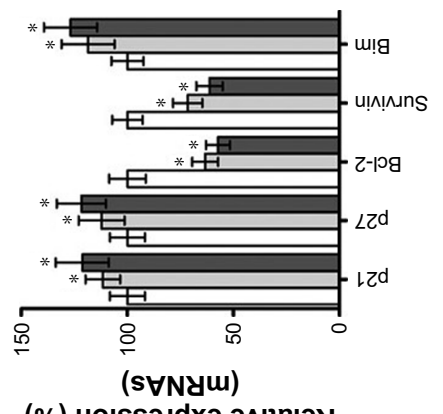

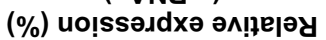

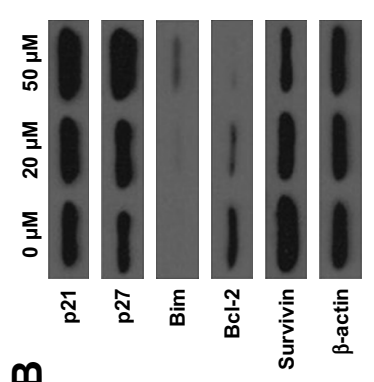


Table 2 The signal pathways involved in circRNAs and IncRNAs

\begin{tabular}{llll}
\hline Gene & Type & Function & Involved signal pathway \\
\hline circUBAP2 & circRNAs & Oncogene & MAPK/ERK \\
circZNF292 & & & Wnt/ $\beta$-catenin, JAK-STAT \\
circHIPK3 & & Wnt/ $\beta$-catenin \\
circTCF25 & & PI3K-Akt \\
HI9 & IncRNAs & JAK/STAT \\
DQ786243 & & PKA/CREB \\
HOXD-ASI & & MAPK/ERK \\
CCATI & & Wnt/ $\beta$-catenin \\
HULC & & Wnt/ $\beta$-catenin, PI3K-Akt \\
circZKSCANI & circRNAs & Suppressor & PI3K-Akt \\
circMTOI & & & Wnt/ $\beta$-catenin, MAPK \\
circITCH & & & Wnt/ $\beta$-catenin \\
GAS5 & & PI3K-Akt \\
CASC2 & IncRNAs & Wnt/ $\beta$-catenin \\
ANCR & & PI3K-Akt \\
MEG3 & & Wnt/ $\beta$-catenin \\
\hline
\end{tabular}

the above-mentioned signal pathways. We will continue to explore this further.

\section{Conclusion}

This study shows that the nitrogenous heterocyclic compound inhibits the proliferation of tumor cells and causes their apoptosis and cell cycle arrest. The nitrogenous heterocyclic compound may be a new and potential anti-tumor drug.

\section{Acknowledgments}

This study was supported by the National Natural Science Foundation of China (Grant nos 31501159 and 81601047), Tianjin Public Health Key Research Project (Grant no 15KG108), Tianjin Science and Technology Key Project on Chronic Diseases Prevention and Treatment (Grant no 16ZXMJSY00020), Special Program of Talents Development for Excellent Youth Scholars in Tianjin, China (TJTZJH-QNBJRC-2-9), and Tianjin 131 Creative Talents Cultivation Project (2016).

\section{Disclosure}

The authors report no conflicts of interest in this work.

\section{References}

1. Chio CC, Chen KY, Chang CK, et al. Improved effects of honokiol on temozolomide-induced autophagy and apoptosis of drug-sensitive and -tolerant glioma cells. BMC Cancer. 2018;18:379.
2. Hu W, Tan C, He Y, Zhang G, Xu Y, Tang J. Functional miRNAs in breast cancer drug resistance. Onco Targets Ther. 2018;11:1529-1541.

3. Piano V, Benjamin DI, Valente S, et al. Discovery of inhibitors for the ether lipid-generating enzyme AGPS as anti-cancer agents. ACS Chem Biol. 2015;10(11):2589-2597.

4. Zhu Y, Liu XJ, Yang P, et al. Alkylglyceronephosphate synthase (AGPS) alters lipid signaling pathways and supports chemotherapy resistance of glioma and hepatic carcinoma cell lines. Asian Pac J Cancer Prev. 2014;15(7):3219-3226.

5. Zhu Y, Zhu L, Lu L, et al. Role and mechanism of the alkylglycerone phosphate synthase in suppressing the invasion potential of human glioma and hepatic carcinoma cells in vitro. Oncol Rep. 2014;32(1):431-436.

6. Khamis I, Heikkila JJ. Effect of isothiocyanates, BITC and PEITC, on stress protein accumulation, protein aggregation and aggresomelike structure formation in Xenopus A6 kidney epithelial cells. Comp Biochem Physiol C Toxicol Pharmacol. 2018;204:1-13.

7. Ma YS, Hsiao YT, Lin JJ, Liao CL, Lin CC, Chung JG. Phenethyl isothiocyanate (PEITC) and benzyl isothiocyanate (BITC) inhibit human melanoma A375.S2 cell migration and invasion by affecting MAPK signaling pathway in vitro. Anticancer Res. 2017;37(11):6223-6234.

8. Lai KC, Hsiao YT, Yang JL, et al. Benzyl isothiocyanate and phenethyl isothiocyanate inhibit murine melanoma $\mathrm{B} 16 \mathrm{~F} 10$ cell migration and invasion in vitro. Int J Oncol. 2017;51(3):832-840.

9. Yang B, Li X, He L, Zhu Y. Computer-aided design of temozolomide derivatives based on alkylglycerone phosphate synthase structure with isothiocyanate and their pharmacokinetic/toxicity prediction and antitumor activity in vitro. Biomed Rep. 2018;8(3):235-240.

10. Yang P, Qiu Z, Jiang Y, et al. Silencing of cZNF292 circular RNA suppresses human glioma tube formation via the $\mathrm{Wnt} / \beta$-catenin signaling pathway. Oncotarget. 2016;7(39):63449-63455.

11. Lin JF, Tsai TF, Yang SC, et al. Benzyl isothiocyanate induces reactive oxygen species-initiated autophagy and apoptosis in human prostate cancer cells. Oncotarget. 2017;8(12):20220-20234.

12. Zhu M, Li W, Dong X, et al. Benzyl-isothiocyanate induces apoptosis and inhibits migration and invasion of hepatocellular carcinoma cells in vitro. J Cancer. 2017;8(2):240-248.

13. Park E. Data on cell cycle in breast cancer cell line, MDA-MB-231 with ferulic acid treatment. Data Brief. 2016;7:107-110.

14. Yoon MK, Mitrea DM, Ou L, Kriwacki RW. Cell cycle regulation by the intrinsically disordered proteins $\mathrm{p} 21$ and $\mathrm{p} 27$. Biochem Soc Trans. 2012;40(5):981-988.

15. Han JH, Lee SG, Jung SH, et al. Sesamin inhibits PDGF-mediated proliferation of vascular smooth muscle cells by upregulating p21 and p27. J Agric Food Chem. 2015;63(33):7317-7325.

16. Shen L, Qu X, Li H, et al. NDRG2 facilitates colorectal cancer differentiation through the regulation of Skp2-p21/p27 axis. Oncogene. 2018; 37:1759-1774.

17. Aliparasti MR, Alipour MR, Almasi S, Feizi H. Ghrelin administration increases the $\mathrm{Bax} / \mathrm{Bcl}-2$ gene expression ratio in the heart of chronic hypoxic rats. Adv Pharm Bull. 2015;5(2):195-199.

18. He Y, Liu JN, Zhang JJ, Fan W. Involvement of microRNA-181a and Bim in a rat model of retinal ischemia-reperfusion injury. Int $J$ Ophthalmol. 2016;9(1):33-40.
Drug Design, Development and Therapy

\section{Publish your work in this journal}

Drug Design, Development and Therapy is an international, peerreviewed open-access journal that spans the spectrum of drug design and development through to clinical applications. Clinical outcomes, patient safety, and programs for the development and effective, safe, and sustained use of medicines are the features of the journal, which

\section{Dovepress}

has also been accepted for indexing on PubMed Central. The manuscript management system is completely online and includes a very quick and fair peer-review system, which is all easy to use. Visit http://www.dovepress.com/testimonials.php to read real quotes from published authors.

Submit your manuscript here: http://www.dovepress.com/drug-design-development-and-therapy-journal 